\title{
THE PREDICTION OF PARKING SPACE AVAILABILITY
}

\author{
Helena BROŽOVÁ ${ }^{1}$, Miroslav RƯŽIČKA ${ }^{2 *}$ \\ ${ }^{1}$ Faculty of Economics and Management, Czech University of Life Sciences Prague, Czech Republic \\ ${ }^{2}$ Faculty of Engineering, Czech University of Life Sciences Prague, Czech Republic
}

Received 5 December 2018; revised 5 April 2019, 5 June 2019; accepted 4 July 2019

\begin{abstract}
Intelligent Parking Systems (IPS) allow customers to select a car park according to their preferences, rapidly park their vehicle without searching for the available parking space (place) or even book their place in advance avoiding queues. IPS provides the possibility to reduce the wastage of fuel (energy) while finding a parking place and consequently reduce harmful emissions. Some systems interact with in-vehicle navigation systems and provide users with information in real-time such as free places available at a given parking lot (car park), the location and parking fees. Few of these systems, however, provide information on the forecasted utilisation at specific time. This paper describes results of a traffic survey carried out at the parking lot of supermarket and the proposal of the model predicting real-time parking space availability based on these surveyed data. The proposed model is formulated as the non-homogenous Markov chains that are used as a tool for the forecasting of parking space availability. The transition matrices are calculated for different time periods, which allow for and include different drivers' behaviour and expectations. The proposed forecasting model is adequate for potential use by IPS with the support of different communication means such as the internet, navigation systems (GPS, Galileo etc.) and personal communication services (mobile-phones).
\end{abstract}

Keywords: intelligent parking systems, prediction, parking space availability, non-homogenous Markov chain, traffic survey.

\section{Notations}

\section{Abbreviations}

GBS - gross building square;

GFA - gross floor area;

GPS - global positioning system;

IPRS - intelligent parking reservation service;

IPS - intelligent parking system (or service);

MADM - multiple attributes decision-making;

MAPE - mean absolute percentage error;

PCS - personal communication service;

PGI - parking guidance and information.

\section{Variables and functions}

$E\left(i_{A}\right)$ - expected parking lot state in period $t_{A}$ from model database;

$E\left(i_{A}^{M}\right)$ - forecasted expected state in period $t_{A}$;

$E\left(i_{Q}\right)$ - expected parking lot state in period $t_{Q}$ from model database;

$f_{i}(t)-$ frequency of state $i$;

$f_{i j}(t)$ - frequency of transitions from state $i$ to state $j$;

$i, j, k$ - states of process;

$i_{Q}^{M}-$ actual parking lot state; $m_{i}(t)$ - surveyed number of occurrences of state $i$;

$m_{i j}(t)$ - surveyed number of transitions from state $i$ to state $j$;

$n$ - number of states;

$P(t)$ - transition matrix in time $t$;

$p_{i}(t)$ - probability of state $i$ in time $t$;

$p_{i j}(t)$ - one-step transition probability between states $i, j$ in time $t$;

$p(t)$ - vector of states probabilities in time $t$;

$p\left(t_{A}\right)$ - vector of states probabilities in period $t_{A}$ from model database;

$p\left(t_{Q}\right)$ - vector of states probabilities in period $t_{Q}$ from model database;

$p^{M}\left(t_{A}\right)$ - forecasted vector of states probabilities in pe$\operatorname{riod} t_{A}$;

$p^{M}\left(t_{Q}\right)$ - actual vector of states probabilities in period $t_{Q}$;

$t$ - time;

$T_{A}$ - expected time arrival from period $t_{A} ;$

$T_{Q}$ - query time from period $t_{Q}$;

$X=\left\{X_{t}, t=0,1, \ldots\right\}-$ stochastic process.

${ }^{*}$ Corresponding author. E-mail: ruzicka@tf.czu.cz 


\section{Introduction}

The procedure to determine area parking demand in the Czech Republic is generally carried out in the following three basic approaches. The first one is the usage of standards (ČSN 73 6056, ČSN 73 6110), the second one is based on zoning regulations (Rada hlavního města Prahy 2016) and the third one is modelling of planned parking spaces (places) (Bosserhoff 2009; Cheng et al. 2012; Martolos et al. 2013). The principle of all these approaches is based on planned squares defined, e.g., as GBS, GFA or sale floor surface and so on. Consequently, different square quantities (square units) are taken as the generator of the number of customers, of students, of clerks, of transit frequency, of passenger cars per time (trip generation rate), parking generation rate and other information are derived from experience based on pre-carried out traffic surveys. These parking space projects are often further modified and particularized by different influences (with the usage of several coefficients) as for urban, suburban, and rural areas or for a type of shopping, density of population, transit accessibility, offer of special goods, discount actions, the growth of motor vehicles number per capita, etc. Shoup (1999) discussed these procedures and pointed out several discrepancies in number, place and duration of the traffic surveys, the relation validity between generation rates and GFA and accepting conclusions based on these presumptions. Nevertheless, none of these procedures prevents occurring problems linked with the current parking, congestions and traffic flows. The design and development of sustainable transport systems and alternative transport modes will lead to the reduction of car usage in the future. Nowadays, however the support of the wider usage of public transport or modal shift to solve environmental problems is not sufficiently accepted by public. Everyday reality in many cities shows that it does not meet always with success and people still prefer to use passenger cars especially for shopping. Results of psychology studies imply that reducing car use must be promoted by emphasizing the positive consequences of reducing car use (De Groot et al. 2008). Yan et al. (2019) simulated policy results and they found out some synergistic effects between policy measures; when pricing and policy measures reducing search and egress time are combined, they shape parking demand more than the sum of their individual effects if isolated implementation.

Searching for parking spaces on car parking lots (e.g., public $\mathrm{P}+\mathrm{R}$, supermarket, shopping centres lots with free or charged access) or on streets has significant spill-over effects on the urban traffic. For example, under-priced onstreet parking (during peak periods) can exacerbate urban traffic congestion by inducing drivers to cruise for the inexpensive parking spaces. Looking for a free parking place is a tedious task since in urban scenarios up to $40 \%$ of traffic is generated by cruising vehicles (Richter et al. 2014). From the driver's point of view, however, finding a free parking place is just difficult and tedious in both cases.
The contemporary designed and used IPS systems (called PGI as well) are aimed to support drivers' searching, inter alia, for vacant parking spaces. However, these systems can be only successfully utilized if adequate levels of demand and supply of parking places are available in the acceptable vicinity of the driver's destination.

Lin et al. (2017) show that existing and ongoing works on smart parking are complicated and transdisciplinary and that many varied works involve multiple disciplines, which are closely linked and inseparable. They went through the literature over the period of 2000-2016 on parking solutions as they were applied to smart parking development and evolution. They proposed three macrothemes to classify parking, i.e., information collection, system deployment, and service dissemination. They also point out to information and communication technology evolution, drivers can more efficiently find satisfying parking spaces with smart parking services.

The influences on driver's decision for a given parking alternative is a topic of many studies that consider factors as walking distance or distance to destination, driving and waiting time, parking fees, service level of parking lots, safety, expected number of available parking spaces, etc. (Hendricks, Outwater 1998; An et al. 2004; Lam et al. 2006; Caicedo 2009).

Khaliq et al. (2019) estimated model showing that almost all these attributes such as parking costs, payment options, expected parking duration, speed limit, level of parking convenience, space availability and surrounding activities play a considerable role when determining car drivers' parking preferences. The model highlights relatively important road related attributes, which can induce search traffic and can be valuable for local authorities.

Parking surveys have the significant importance for the parking managers and corresponding planners or researchers. Chen et al. (2016) work on the technical basis (sensors layout and algorithms) for parking survey in IPS where parking spaces, entrance and exit are detected to acquire the occupation of the parking; they presented three possible sensor layouts and corresponding algorithms to obtain the characteristic index needed in parking survey. D'Aloia et al. (2015) supposed that unmanned aerial vehicles (drones) can be used to recognize free parking spaces, pictures of urban areas captured by the on-board camera. It shows interesting possibilities of management of parking areas and specifically the detection of parking slot occupancy. Support of drivers' decision depends on the collection, storage, dissemination and use of traffic and parking data. Zhao et al. (2018) described a system supporting the intelligent parking through which data acquisition and storage of parking information could fully automatically take part. To analyse parking information, they proposed a new traffic model to forecast the status of urban traffic in order to improve the efficiency of urban transportation.

IPS can provide information to users in real-time such as parking location, free capacity, fees and current parking utilization (Inaba et al. 2001; Oh et al. 2002; Yang et al. 
2003). However, few of these systems provide information on the forecasted utilization at specific time. IPRS even allow customers to select and book a parking facility according to their preferences, rapidly park without searching (cruising) for a free parking place, and eventually pay their reservation in advance avoiding queues.

Many authors researched the finding available parking spaces with the use of the vehicular ad hoc networks and models (Caliskan et al. 2007; Mathur et al. 2010). The principle of ad hoc networks and the internet of things (spontaneous creation of a wireless network for vehicle-tovehicle data exchange and communication) could be a basis for solving the problem of finding a free parking space and possibly its reservation and payment. It can be carried out by linking IPS with PCS and car GPS navigation or vehicular ad hoc networks. Stolfi et al. (2017) presented the web page prototype to visualize the current and historical parking data on a map, and used different models of the occupancy forecast to satisfy drivers parking needs.

Many different types of models are listed for IPS in the literature, e.g., the neuron networks and deep learning (Camero et al. 2019; Rong et al. 2018); the fuzzy approach (Sun et al. 2018); the models of the game theory (Li et al. 2014; Mamandi et al. 2015); the stochastic algorithms, multi logit models, and simulation (Schlote et al. 2014; Liang et al. 2017); the geometric programming (Balzano, Vitale 2017); MADM models (Li et al. 2017).

In the US 2004/0032342 used a database that stored information to project space availability at each parking facility (parking lot entries and exits, historical information of vehicle traffic to the parking lot over time, and duration of stays at the parking lot), and the system operates with data obtained from ongoing survey for remote parking lots with high demand. In the US 2004/0032342 patented system to forecast parking availability for a time in the future based on driver-reported estimations of how long each vehicle in the parking area will stay and on forecasted arrivals. Caicedo et al. (2012) objected to US 2004/0032342 access that it does not consider characterization of driver's behaviour in choice making. Caicedo et al. (2012) proposed methodology consisted of three subroutines to allocate simulated parking requests, estimate future departures, and forecast parking availability. Parking requests were allocated iteratively using an aggregated approach as a function of simulated drivers' preferences and parking availability. This approach was based on the calibrated discrete choice model for selecting parking alternatives. It was concluded that results obtained from comparison of predictions and real data yielded small average error availabilities. The forecast improves as the system registers arrivals and departures.

Klappenecker et al. (2014) followed Caliskan et al. (2006) and discussed the problem of predicting the number of available parking spaces in a parking lot. They tried to respond drivers' questions as:

- "will a parking space at a particular parking area be available when I get there in time $t$-minutes?";
- "there is no parking space available, how long do I need to wait until a parking space becomes available?".

These questions were solved with the modelling using continuous-time Markov chain. Klappenecker et al. (2014) assumed homogeneous Markov chain and their paper also collected numerous works studying the problem of finding available parking spaces using a vehicular ad hoc network as well. Klappenecker's approach considerably simplifies the computation of the transition probabilities in the vehicle navigation system and processing of probability data of available parking space upon arrivals. Nevertheless, the proposed method was applied under the theoretical conditions of large parking lot (1000 parking places) and the assumption of homogeneity with constant parking demand in time. The assumption of homogeneity seems to be rather theoretical; because the drivers' behaviour is changing during the day time and depends on the day of week, etc. The utilization of the Markov chain is also described in researches by Li et al. (2017) and Tilahun, Di Marzo Serugendo (2017). The last authors highlighted many possible reasons of non-homogeneity of the process of parking lot usage. They also suggest process of updating the transition matrices and possibility of cooperation between near parking lots.

The aim of this paper is to design and verify the new model of parking space availability using non-homogenous Markov chain under real conditions of parking lot approximately up to 100 parking spaces based on the results of carried out traffic survey. The condition of traffic survey and Markov model will be briefly described at the first part of the paper and next part consist of the proposal of the model predicting real-time parking space availability derived from these surveyed data. The last part of paper consists of study cases and presents process of prediction and analysis of its accuracy.

\section{Materials and methods}

\subsection{Parking lot}

The selected parking lot of supermarket was use to verify the model. The full-assortment supermarket with GBS $1650 \mathrm{~m}^{2}$ is an ordinary example of the most spread commercial facilities in the Czech Republic. Supermarkets with similar GBS and parking lots are built throughout the whole Europe. There are shopping hours from 7 a.m. to $8 \mathrm{p} . \mathrm{m}$. there and the supermarket is opened for the whole week (Saturday and Sunday opened at 8 a.m.). The number of offered parking places is 86 (reserved 7 places for disabled people and people with prams) with free access, i.e., no barriers or any other payment facility. The traffic survey was carried out during the whole week, from Monday to Sunday, from 6 a.m. to 9 p.m. in the last week of September 2017. The supermarket is located in the Prague's suburban area with near two bus stops of public transport (3...4 min walk distance). 
The parking data were obtained under the real traffic conditions of surveyed ordinary parking lot of supermarket. The purpose of this survey was to obtain suitable and sufficient data for the quantification of non-homogenous Markov chain model.

\subsection{Markov chain}

Markov chain (Serfozo 2009), is commonly used for modelling of the stochastic processes discrete in time and states with Markov property, which means that the next state of the stochastic process $X$ depends only on its last state:

$$
\begin{aligned}
& p_{i j}(t)=P\left\{X_{t}=i \mid X_{t-1}=j_{t-1},\right. \\
& \left.X_{t-2}=j_{t-2}, \ldots, X_{0}=j_{0}\right\}=P\left\{X_{t}=i \mid X_{t-1}=j_{t-1}\right\} .
\end{aligned}
$$

This probability is referred to as a one-step transition probability $p_{i j}(t)$. Matrix of all transition probabilities is called transition matrix $P(t)$, which has the number of rows and columns equal to the number of the states. If the transition probabilities vary with the time $t$, the process $X$ would be a non-homogeneous Markov chain and the transition matrices for each time step $t$ are necessary for its description. If the Markov chain has finite number of states, we can define row vector of probabilities that Markov chain is in the time $t$ in its states $1,2, \ldots, n$ :

$$
p(t)=\left(p_{1}(t), p_{2}(t), \ldots, p_{n}(t)\right), t=1,2, \ldots, n .
$$

From the Chapman-Kolmogorov equations we can calculate the probabilities of the Markov chain states in some future time $t$. If we know the initial distribution $p(0)$ and one-step transition matrices $P(0), P(1), \ldots, P(t-1)$ then we can compute $p(t)$ using the formula (Serfozo 2009):

$$
\begin{aligned}
& p(t)=p(0) \cdot P(0) \cdot P(1) \cdot \ldots \cdot P(t-1)= \\
& p(1) \cdot P(1) \cdot \ldots \cdot P(t-1)=p(t-1) \cdot P(t-1) .
\end{aligned}
$$

\section{Parking spaces availability predicted by non-homogenous Markov chain}

The proposal of forecasting model is based on the nonhomogenous Markov chain, which is used as a tool to predict the parking space (place) availability. The transition matrices are calculated for all different times and allow including of different drivers' behaviour and expectations.

The first assumption in proposed model design is that the process describing the number of used (or available) parking places can be modelled as non-homogenous Markov chain. The number of arriving of passengers' cars into a parking lot can be modelled by Poisson's process and can be seen as non-homogenous process. As mentioned earlier it is not possible to assume that processes (arrivals/departures of cars, i.e., intensities) are homogenous in time, because these intensities depend on a specific time of day (e.g., peak hours), on a day of week and eventually on other circumstances. Therefore, this process can be seen as a random walk representing a quantity that changes over time. The number of available parking places in time $t$ depends on number of places in time $t-1$ and number of arriving/departing cars in this time. Analysis of the real data also shows that the number of available parking places depends on time of the day and the day of the week. Therefore, the model was quantified for the working days only due to high similarity of process of parking spaces availability during these days. Similarly, its version could be quantified for weekend days as well.

The construction of non-homogenous Markov chain model requires knowledge of the possible states of modelled process, its probabilities and the transition matrices for all time steps. The parking lot of supermarket data obtained by traffic survey are used for calculation of model input.

The definition of the Markov chain states is based on the aggregation of surveyed data into categories of tens available/occupied spaces. By this approach, the situations of parking place can be divided into following proposed states. Each state represents number of tens of parking cars and consequently the number of available spaces. Number of states depends on the maximal capacity of parking lot. Generally, it is possible to propose more detailed states (shorter intervals for number of cars), which could result into more detailed conclusions; but such amount of results would not have provided a simple overview about forthcoming parking lots occupancy.

The 9 states were proposed for the parking lot with maximal capacity of signed 86 parking places. Each state describes number of parking cars as well as available (nonoccupied) parking places (Table 1).

The probabilities of Markov chain states and transition probabilities in specific time are estimated based on the number of occurrences of individual states and individual transitions between the states in the observed data and following two assumptions.

Numbers of arrivals and departures at the parking lot was monitored every $15 \mathrm{~min}$. This $15 \mathrm{~min}$ interval was taken as time interval providing sufficient information about occupancy of parking lot. It means that each $15 \mathrm{~min}$

Table 1. State definition of parking lot

\begin{tabular}{|c|l|l|}
\hline State & \multicolumn{2}{|c|}{ Description of state } \\
\hline State 1 & $0 \ldots 10$ parking cars & $\begin{array}{l}>76 \text { parking places available }- \\
\text { free parking lot }\end{array}$ \\
\hline State 2 & $11 \ldots 20$ parking cars & $66 \ldots 75$ available parking places \\
\hline State 3 & $21 \ldots 30$ parking cars & $56 \ldots 65$ available parking places \\
\hline State 4 & $31 \ldots 40$ parking cars & $46 \ldots 55$ available parking places \\
\hline State 5 & $41 \ldots 50$ parking cars & $36 \ldots 45$ available parking places \\
\hline State 6 & $51 \ldots 60$ parking cars & $26 \ldots 35$ available parking places \\
\hline State 7 & $61 \ldots 60$ parking cars & $16 \ldots 25$ available parking places \\
\hline State 8 & $71 \ldots 80$ parking cars & $6 \ldots 15$ available parking places \\
\hline State 9 & $81 \ldots 86$ parking cars & $\begin{array}{l}<5 \text { parking places available }- \\
\text { occupied parking lot }\end{array}$ \\
\hline
\end{tabular}


number of occupied, respectively available, parking places were known. The number $m_{i}(t)$ of occurrences of state $i$ in time $t$ is calculated as the number of all observations in which the number of parking cars is within state $i$. The number $m_{i j}(t)$ of transitions from state $i$ to state $j$ in time $t$ is similarly calculated as the number of all observations in which the number of parking cars is changed from state $i$ into the state $j$ in time $t$.

The second assumption is that the number of arrivals to the parking lot does not need to share an exact scheme without delays or advance. This assumption was proposed based on maximal one-hour delay or advance as possible shift of process on time axis. That is why the calculation of state frequencies at specific time and transition probabilities for the stated time interval is supposed to be with a wider range of time intervals also. It means that data of more surveyed intervals before and after specific time $t$ have to be used for this calculation. Therefore, the frequencies of transitions are calculated in the range of surveyed changes from previous and following time periods. The time periods $t-3, t-2, t-1, t, t+1, t+2, t+3$ were chosen. The weighted calculation of relative transition frequencies is used. Period distances are considered and their influences are expressed by weights; i.e., periods $t-3$ and $t+3$ have weight $1, t-2$ and $t+2$ have weight 2 , $t-1$ and $t+1$ have the weight 3 and period $t$ is weighted by 4 (Figure 1 ).

There is suggested the transition frequencies calculation with the use of following equation:

$$
\begin{aligned}
& f_{i j}(t)=m_{i j}(t-3)+2 \cdot m_{i j}(t-2)+ \\
& 3 \cdot m_{i j}(t-1)+4 \cdot m_{i j}(t)+ \\
& 3 \cdot m_{i j}(t+1)+2 \cdot m_{i j}(t+2)+m_{i j}(t+3), \\
& i, j=1,2, \ldots, n .
\end{aligned}
$$

The same principle was used to calculate the state frequencies of parking lot occupancy:

$$
\begin{aligned}
& f_{i}(t)=m_{i}(t-3)+2 \cdot m_{i}(t-2)+ \\
& 3 \cdot m_{i}(t-1)+4 \cdot m_{i}(t)+ \\
& 3 \cdot m_{i}(t+1)+2 \cdot m(t+2)+m_{i}(t+3), \\
& i=1,2, \ldots, n
\end{aligned}
$$

The third assumption is that it is possible to suppose that transitions are more probable between neighbouring states $k \rightarrow k, k \rightarrow(k-1), k \rightarrow(k+1)$ (where $k$ is a specific

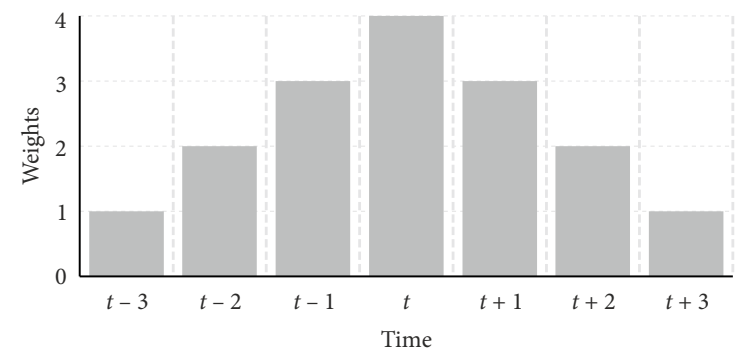

Figure 1. Description of weights of transition frequencies state). Therefore, the frequencies of transition between grades $k \rightarrow k, k \rightarrow(k-1), k \rightarrow(k+1)$ are increased by specific constant $c$ to ensure its non-zero value assuming that this transition frequency will never have zero value. This proposed model of small parking lot based on oneweek survey uses $c=1$. The calculation of all probabilities necessary for Markov chain model definition will be based on the above calculation of the state frequency $f_{i}(t)$ and of the transition frequency $f_{i j}(t)$. The following equation was suggested for transition probability calculation:

$$
p_{i j}(t)=\left\{\begin{array}{l}
\frac{f_{i j}(t)}{\sum_{j=1}^{n} f_{i j}(t)} \text { if } i \neq j, j+1, j-1 ; \\
\frac{f_{i j}(t)+1}{\sum_{j=1}^{n} f_{i j}(t)} \text { else; }
\end{array} i, j=1,2, \ldots, n,\right.
$$

and the following equation for states probability calculation:

$$
p_{i}(t)=\frac{f_{i}(t)}{\sum_{j=1}^{n} f_{j}(t)}, i=1,2, \ldots, n .
$$

\subsection{Model testing}

The proposed model was tested by the comparison of the real-time series of the observed parking lot states and the results received from the suggested Markov chain model. Data of the working days were used only as it was already explained above. The MAPE was used as a measure of prediction accuracy of a forecasting by proposed Markov chain model in comparison with observed time series. MAPE expresses accuracy as a percentage. The percentage error is between 10 and $20 \%$ (Table 2) when the comparison of the modelled data with the working days' data is carried out.

Table 2. MAPE values of forecast error

\begin{tabular}{|c|c|c|c|c|c|}
\cline { 2 - 6 } \multicolumn{1}{c|}{} & Monday & Tuesday & Wednesday & Thursday & Friday \\
\hline MAPE & 0.130 & 0.173 & 0.118 & 0.165 & 0.146 \\
\hline
\end{tabular}

The quality of model prediction is much higher; there is only $8.4 \%$ error, when the modelled time series is compared with the average working days' data. Although the model data are based only on the week's traffic survey, it is possible to say that the proposed model describes the use of the parking lot with a high accuracy.

\subsection{Possibilities of model update}

The Markov chain model should be updated, as the nonhomogeneity occurs due to many expected or unexpected events. The time appropriate matrices of transition probabilities and vectors of state probabilities can be recalcu- 
lated after the adding of the number of newly observed state occurrences and transitions to the past values $m_{i}(t)$ and $m_{i j}(t)$ to receive the actual value of frequency. This addition influences the calculation of the appropriate matrixes of transition probabilities and vectors of surveyed state probabilities.

The problems might occur when the initial data have not been collected for a sufficiently long period because each and even the small change is significant. Then this eventually online model updating can produce a great instability.

Therefore, the online (continuous) updating of the model can only be performed after a longer period of time when the long series of data is integrated into the model. In this case, every change of the number of transitions can be observed as relatively small and the model behaviour will become stable and more precise.

From this reason, the model updating at the beginning of use should not be made continuously but at least after, e.g., the whole day or week monitoring only. This means it is necessary to process newly recorded data daily (or weekly) and use them for updating the model quantification.

\subsection{Model forecasting and model application}

This paper proposes the following model application to predict the parking place availability for the needs of incoming drivers.

Let us suppose that the PCS has sent the query to the nearest (or unique) parking lot, respectively to its IPS. The forecast of forthcoming occupancy of parking lot requires just knowledge of current parking lot situation and the matrices of transition probabilities between states during the observed time period, and the calculation of probabilities of the states according to the Equation (3). The forecast process consists of the following 4 steps.

In the first step, the query time $T_{Q}$ and expected arrival time $T_{A}$ and actual parking lot state $i_{Q}^{M}$ are registered. Let $T_{Q}$ is time from period $t_{Q}$ and $T_{A}$ from period $t_{A}$. The transition matrices $P\left(t_{Q}\right), P\left(t_{Q}+1\right), \ldots, P\left(t_{A}-1\right)$ and vectors of state probabilities $p\left(t_{A}\right)$ and $p\left(t_{Q}\right)$ are read from the model database.

The second step of proposed model application consists of comparison of the situation in time $T_{Q}$ with the situation in corresponding time interval from the model database. Two comparisons are made:

- comparing the actual state $i_{Q}^{M}$ and expected state calculated based on the data from the model database as:

$E\left(i_{Q}\right)=p\left(t_{Q}\right) \cdot(1,2, \ldots, n)^{T} ;$

- comparing the vector $P\left(t_{Q}\right)$ from model database and the actual vector of states probabilities $p^{M}\left(t_{Q}\right)$ where 1 is on the position of the state $i_{Q}^{M}$ :

$p^{M}\left(t_{Q}\right)=(0, \ldots, 1, \ldots, 0)$.
In the third step, the forecast is made:

- the forecast probability vector $p^{M}\left(t_{A}\right)$ of parking place availability in the arrival time $T_{A}$ is calculated using equation:

$p^{M}\left(t_{A}\right)=p^{M}\left(t_{Q}\right) \cdot P\left(t_{Q}\right) \cdot P\left(t_{Q}+1\right) \cdot \ldots \cdot P\left(t_{A}-1\right) ;$

- the forecast state in the arrival time $T_{A}$ is calculated as expected value of a discrete random variable:

$E\left(i_{A}^{M}\right)=p^{M}\left(t_{A}\right) \cdot(1,2, \ldots, n)^{T}$.

In the fourth step, comparison of the forecasted situation with the data from model database is made:

- the forecasted probability vector $p^{M}\left(t_{A}\right)$ is graphically compared with vector $p\left(t_{A}\right)$ from model database;

- the forecasted state $E\left(i_{A}^{M}\right)$ is compared with the expected state according to the model database calculated as:

$E\left(i_{A}\right)=p\left(t_{A}\right) \cdot(1,2, \ldots, n)^{T}$.

All these results are displayed on PCS. Both comparisons are important to analyse and eventually detect some possible non-standard situations occurring at the parking lot. The more the initial situation differs from past observations the more likely the model forecast would be different from the future situation. If the comparison of the data in time $T_{Q}$ shows a high match then the more relevant prediction of the situation in time $T_{A}$ at the parking lot is obtained in the fourth step.

\section{Case study}

The process of data survey and the overall description of parking lot is specified in this section. Two examples providing explanation of model usage for standard and non-standard situation at the parking lot follow. The main purpose of their presentation is to point out the usefulness of the proposed model.

\subsection{Results of traffic survey}

The parking lot was selected according to following criteria: parking lot at "full-assortment shop", usually called supermarket, with shopping time (opening hours) during the whole day (from 7 a.m. to 8 p.m.); GBS of supermarket $1000 \ldots 2000 \mathrm{~m}^{2}$; free access to the parking lot; intensities should not be influenced by near specific large facility or plant (e.g., large factory, university, etc.).

The aim of a carried-out traffic survey was to count number of arriving and departing vehicles in/from a parking lot (intensities), to find out the type of vehicles (passenger cars, vans, trucks, etc.) and duration of parking vehicles there.

The traffic survey was carried out to record data in 15 min interval and vehicles intensities (frequency of arrivals and departures) were recorded and saved. The total number of parking cars during the whole week was 9558, 
maximal values were find out on Thursday 1648 cars and Friday 1649 cars, minimal value on Sunday 991 cars. The structure of traffic flow (type of vehicles) was uniform, i.e., passenger cars and occasionally vans (no trucks). Figure 2 shows the intensities of arriving and departing cars into/from the parking lot during the hours of the days of surveyed week. It can be point out that even this relatively small parking lot proves high parking turnover (approximately 4 vehicles shared one parking place during the peak hours).

Numbers of occupied parking places per hour every day of the week are shown in the Figure 3. There are some moments when parking lot was occupied with number of cars above the maximal capacity of parking lot. It can be explained that these cars were just exchanging the same parking place, or were parked in non-parking places or even in a space for pedestrians. In case of parking lot with controlled access and counted arrivals and departures, it would be possible to avoid overlapping of the maximal parking capacity.

It is evident that the process of arriving and departing and therefore the number of parking cars depends on the week day and mainly on the hour of day and therefore it is possible to conclude that this process is non-homogenous. At the same time, the high values of the correlation coefficients (Table 3) show that the drivers' behaviour and parking needs are equivalent mainly during working days from Monday to Friday.

This parking lot is not usually fully occupied, but at least 65 parking places are occupied in more than $25 \%$ of time intervals, mainly at the peak hours. Even under this parking turnover, the driver is face to his/her decision where to park. The driver does not usually know before his/her arrival whether unoccupied parking place can be found there.

The data of the whole week traffic survey indicate that $74 . . .78 \%$ of passenger cars spend more than $5 \mathrm{~min}$ and less than half an hour on the parking lot. The passenger cars that have been parked there for less than $5 \mathrm{~min}$ are only $7 \ldots 10 \%$ only. These cars very often just provide transport for another person and immediately leave the parking lot. Passenger cars that spend time from $30 \mathrm{~min}$ to $1 \mathrm{~h}$ are $14 \ldots 20 \%$. The specific number of passenger cars stay there for long time but it might be expected that parking lot of supermarket might be used for another purpose then just to visit the supermarket. It is possible to summarize that $81 \ldots 88 \%$ of passenger cars (without "short comers" up to $5 \mathrm{~min}$ ) are on parking place less than $1 \mathrm{~h}$. The examples of parking time of cars are shown in Figure 4. These two days were chosen to present an ordinary situation at parking lot; weekend days are not so busy but costumers stay at the parking lot similar time.

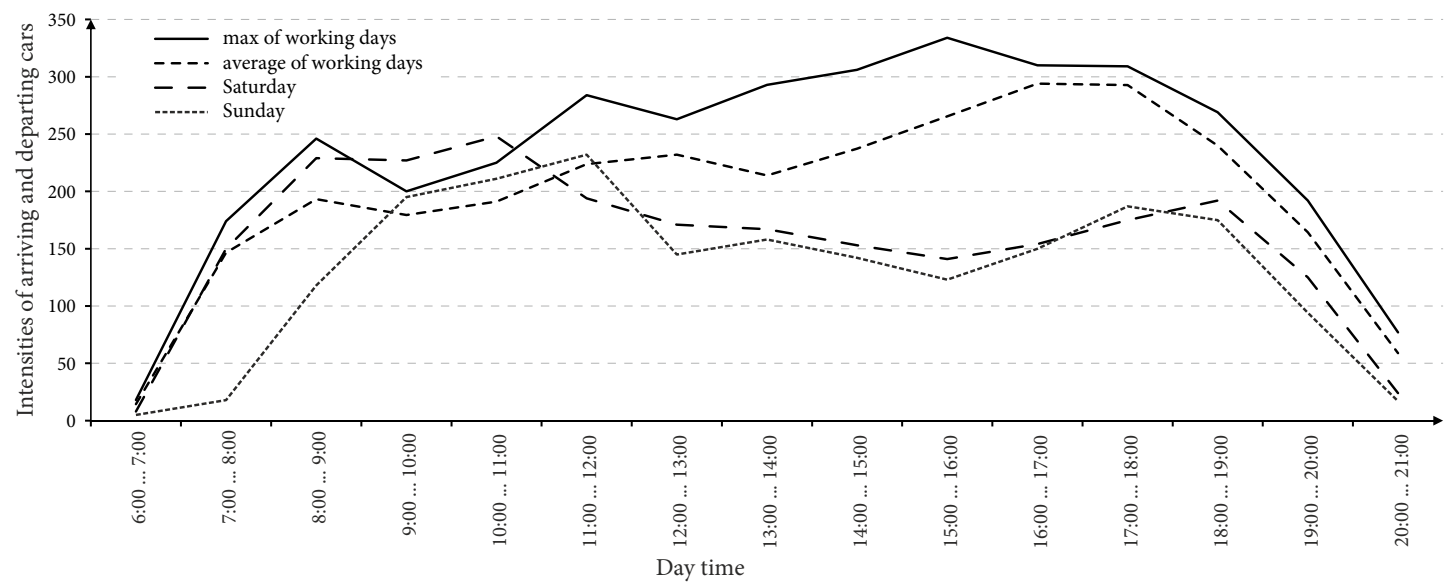

Figure 2. Intensity of arriving and departing cars during hours of weekdays

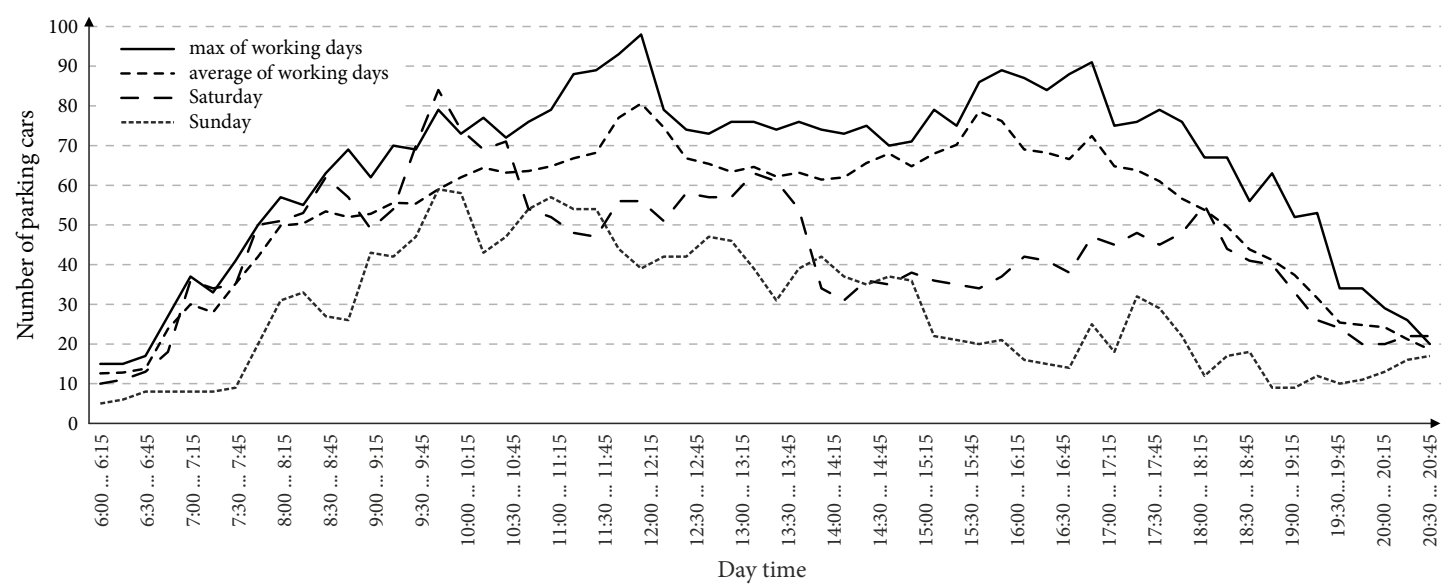

Figure 3. Numbers of occupied parking places during days of week in time 
Table 3. Correlation of parking lot occupancy during days of the week

\begin{tabular}{|l|c|c|c|c|c|c|c|}
\cline { 2 - 7 } \multicolumn{1}{c|}{} & Monday & Tuesday & Wednesday & Thursday & Friday & Saturday & Sunday \\
\hline Monday & 1 & & & & & & \\
\hline Tuesday & 0.793 & 1 & & & & & \\
\hline Wednesday & 0.889 & 0.816 & 1 & & & & \\
\hline Thursday & 0.824 & 0.847 & 0.855 & 1 & & & \\
\hline Friday & 0.828 & 0.802 & 0.890 & 0.843 & 1 & & \\
\hline Saturday & 0.720 & 0.400 & 0.613 & 0.585 & 0.633 & 1 & \\
\hline Sunday & 0.793 & 0.410 & 0.669 & 0.503 & 0.583 & 0.735 & 1 \\
\hline
\end{tabular}

Note: low correlation is grey highlighted.
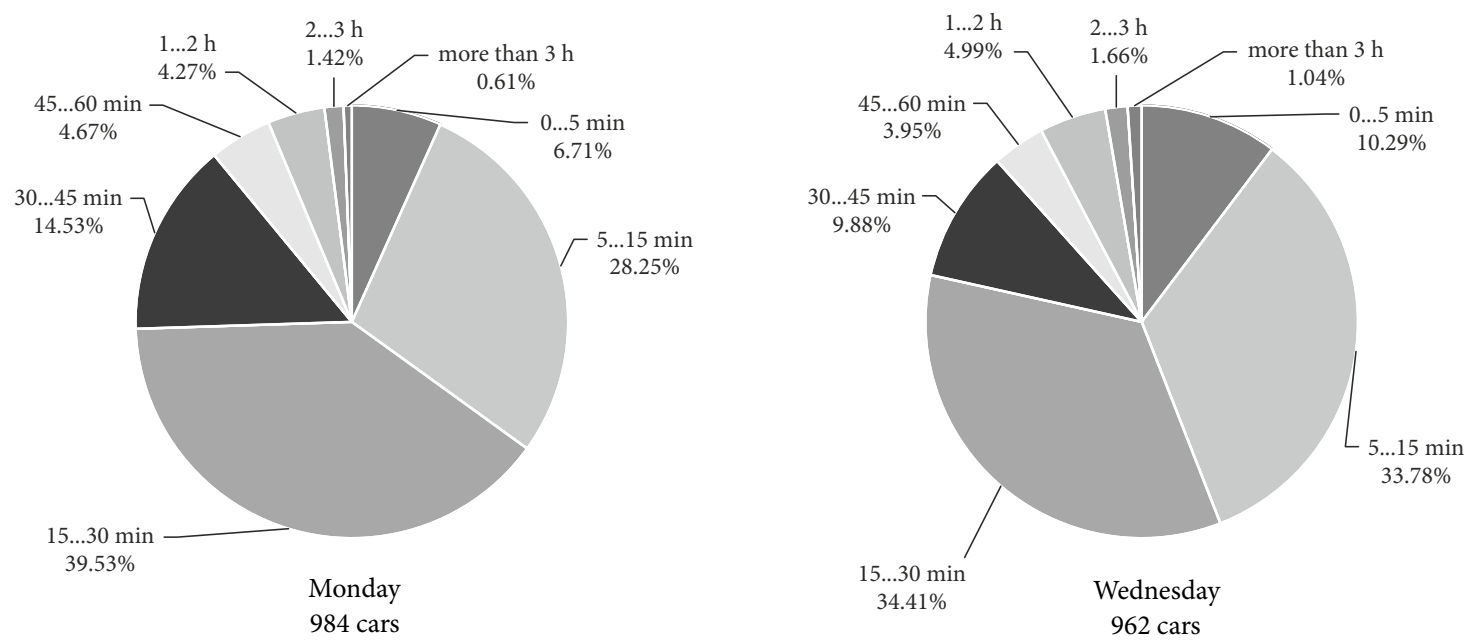

Figure 4. Parking time - example of two days (Monday, Wednesday)

The model proposal and its testing used all surveyed data; even the data of cars that were in the parking lot for less than $5 \mathrm{~min}$. These cars enter the parking lot, they are registered at the entrance and they are expected to spend there "usual time" (i.e., more than $5 \mathrm{~min}$ ) for parking. It is difficult to recognise the intention of arriving drivers and that is why it is necessary to involve them into the model.

It is possible to see that the parking lot is not usually fully occupied, but at least 65 parking places are occupied in more than $25 \%$ of time intervals, mainly at the peak hours. Even under this parking turnover, the driver is face to his/her decision where to park because the driver does not usually know before his/her arrival whether unoccupied parking place can be found there. Even in case there are unoccupied places in parking lot majority of drivers attempt to park in the closest distance from the supermarket entrance and they look for unoccupied places. Notwithstanding the specific parking lot does not reach $85 \%$ occupancy and the driver will find unoccupied place with a high probability, this parking survey can be used for model proposal and presentation of model application.

\subsection{Standard situation case}

The driver plans to park his/her car at the chosen parking lot and he/she wants to know if there is (or will be) an available parking place. The driver sent the query by his/ her PCS at the query time $T_{Q}=9: 57$.

In the moment of the sending query, the PCS determines the expected arrival time $T_{A}=10: 21$ that is depending on the car distance from the parking lot considers GPS and traffic information. The IPS of parking lot registers the actual (measured) state $i_{Q}^{M}=6$. The actual vector of states probabilities $p^{M}\left(t_{Q}\right)$ using Equation (9) is:

$$
p^{M}\left(t_{Q}\right)=(0 ; 0 ; 0 ; 0 ; 0 ; 1 ; 0 ; 0 ; 0) \text {. }
$$

The vector of state probabilities from model databased is:

$$
p\left(t_{Q}\right)=(0 ; 0 ; 0 ; 0.088 ; 0.15 ; 0.262 ; 0.225 ; 0.275 ; 0) \text {, }
$$

and the corresponding expected state is $E\left(i_{Q}\right)=6.45$ (Equation (8)).

The measured state $i_{Q}^{M}$ and expected state $E\left(i_{Q}\right)$ in the time $T_{Q}$ are very similar; the difference is less than $10 \%$.

The vector of state probabilities from model database for the time of arrival $T_{A}$ is:

$$
p\left(t_{A}\right)=(0 ; 0 ; 0 ; 0.063 ; 0.138 ; 0.125 ; 0.275 ; 0.4 ; 0),
$$

and corresponding expected state $E\left(i_{A}\right)=6.813$ (Equation (12)).

Based on the transition matrices $P\left(t_{Q}\right), P\left(t_{Q}+1\right), \ldots$, $P\left(t_{A}-1\right)$ from model database; the vector of forecasted 
state probabilities is calculated (Equation (10)):

$$
p^{M}\left(t_{A}\right)=(0 ; 0 ; 0 ; 0.018 ; 0.11 ; 0.216 ; 0.309 ; 0.337 ; 0.011) \text {. }
$$

Finally, the predicted state is $E\left(i_{A}^{M}\right)=6.869$ (Equation (11)).

The predicted state $E\left(i_{A}^{M}\right)$ is near to state 7 , it means $16 \ldots 25$ places are non-occupied. The expected state $E\left(i_{A}\right)$ in the arrival time $T_{A}$ is similar; the difference is again less than $10 \%$.

The Figure 5 shows comparisons of the vectors of states probabilities from model database and from the forecast by the suggested model. Even though the difference in time $T_{Q}$ may seem to be significant, at the expected arrival time $T_{A}$ on the parking lot, there is a great similarity of forecasted states probability based on the current situation and the states probability from the model database.

The comparison of actual (measured) state and state from the model database shows the usual situation. According to the forecasted states probabilities the driver can suppose no more than 25 available parking places at time of his/her arrival with probability at least $30 \%$ but probability of none available parking place is very low (about $1 \%)$. Therefore, the driver can expect to meet with free parking places there.

\subsection{Non-standard situation case}

A driver plans to park his/her car at the chosen destination and he/her wants to know if there is (will be) an available parking place. The driver sent the query by his/her PCS at the query time $T_{Q}=9: 57$.

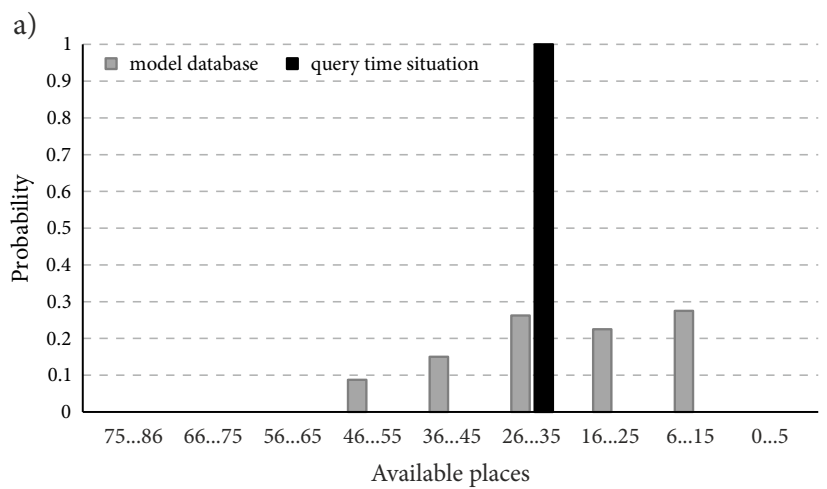

The expected arrival time is $T_{A}=10: 21$ and actual measured state is $i_{Q}^{M}=3$.

Results of the model forecast follow.

Vector of state probabilities in query time $T_{Q}$ is:

$$
p\left(t_{Q}\right)=(0 ; 0 ; 0 ; 0.088 ; 0.15 ; 0.263 ; 0.225 ; 0.275 ; 0) \text {, }
$$

and the expected state $E\left(i_{Q}\right)=6.45$.

The difference between $E\left(i_{Q}\right)$ and $i_{Q}^{M}=3$ is significant (more than $100 \%$ ).

The actual vector of states probabilities $p^{M}\left(t_{Q}\right)$ is:

$$
p^{M}\left(t_{Q}\right)=(0 ; 0 ; 1 ; 0 ; 0 ; 0 ; 0 ; 0 ; 0) \text {. }
$$

Vector of state probabilities in time $T_{A}$ is:

$$
p\left(t_{A}\right)=(0 ; 0 ; 0 ; 0.063 ; 0.138 ; 0.125 ; 0.275 ; 0.4 ; 0),
$$

and the expected state is $E\left(i_{A}\right)=6.813$.

Vector of forecast state probabilities in time $T_{A}$ is:

$p^{M}\left(t_{A}\right)=(0.111 ; 0.222 ; 0.264 ; 0.236 ; 0.167 ; 0 ; 0 ; 0 ; 0 ; 0)$, and the forecast state is $E\left(i_{A}^{M}\right)=3.125$.

The graphical comparison (Figure 6) of the initial data, data obtained from the model database and the model forecasts as well shows that the initial states probabilities represents abnormally empty parking lot.

The predicted state of the parking lot occupancy at the time of arrival $T_{A}$ assumes a maximum half-load of parking lot. However, due to the probability of surveyed states in the model database, it is necessary to assume that ordinary state is a higher number of parking cars, approximately 70 cars, and therefore no more than 15 parking places will be available.

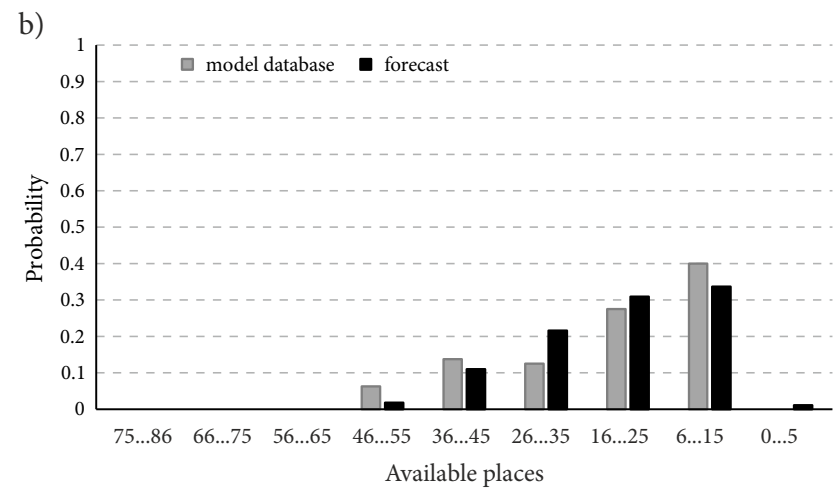

Figure 5. Graphical presentation of the received results for standard situation: $\mathrm{a}$ - situation at query time; $\mathrm{b}$ - forecast for arrival time
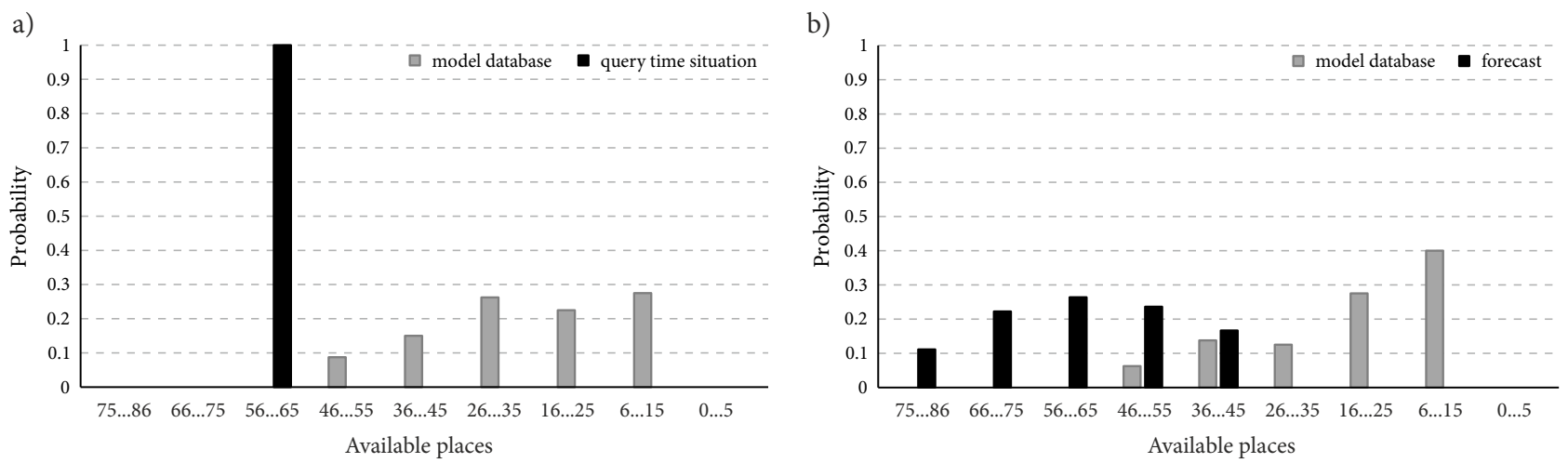

Figure 6. Graphical presentation of the received results for non-standard situation: $\mathrm{a}-$ situation at query time; $\mathrm{b}$ - forecast for arrival time 
In everyday life, the greater or lesser exceptions occur sometimes, which are hard to describe by the model. Therefore, information on the difference between the forecast of the actual (measured) state and the expected state based on the model database is important for the driver. The system is not designed to decide instead of the driver; it just supports the decision-making linked with parking. In addition, by the model data updating, these exceptions will be gradually incorporated into the database.

\section{Conclusions}

The paper presents the non-homogenous Markov chain model for prediction of parking place availability that could be included into IPS (or PGI system) to provide information for incoming drivers in real-time. The proposed usage of Markov chain for modelling of parking place availability has many advantages and novelty.

The difference in presented approach can be seen in the comparison with above-cited references. The suggested model is based on the initial assumption of the nonhomogeneity of the parking utilization process. The model includes time shifts in occupation of parking places and possibilities of continuous updating. The main advantage of proposed model is that it provides information to drivers describing not just the past monitoring situation but also the actual situation on parking lot as well. The majority of scientific works is focused on the finding of expected results or simulations derived from the past as was proved in introduction of this paper and they are not focused on the prediction that is determined and based on the current situation at the parking lot.

If this model would become a part of personal PCS and IPS (or PGI system) of the chosen parking lot (car park) then the model can be used to answer the question: "How many available parking places will be in the car park in the next (specified) time period and with what probability?". The proposed model replies it with possibilities to calculate probabilities of occupancy of parking lots of individual states in future. The final selection of parking lot supposes that these predicted results have to be compared with state probabilities observed for the same time. This solution gives also information about normality or abnormality of the parking lot situation.

The proposed model and its methodology are possible to use for any parking lots. The only condition of its use is that the number of vehicles must be surveyed or simply counted by parking facilities. Parking lot capacity must be known and continuously compared with the instantaneous situation at the parking lot. While tickets can be used as part of identifying the vehicle entering or leaving the parking area, the proposed model could operate by generating an identifier internally for use by the system for parking forecast, and without the need to issue an actual ticket. This identifier could be generated by entry device of the parking lot (e.g., cameras license plate recognition or video-based vehicle counting or any other technical means) that would allow information to be recorded relating to the entry and exit of vehicles in/out the parking lot, stored in the database, and used by the computing means for forecasting. This is important for continuous updating of model database. The use of ad hoc networks and the internet of things can support the solving of some difficulties linked with finding a free parking place; i.e., cooperation of IPS (PGI system) with PCS (mobile-phones) and GPS (navigation) used in passenger cars.

What might be taken as threat of the proposed model is newly constructed objects in a vicinity of the supermarket, e.g., factories, universities, sport facilities, etc. These objects could cause different situations in short time at the parking lot. However, it is necessary to say that after a shorter time the model accepts this new situation due to its updating system and this new situation becomes a part of the model.

As a disadvantage of the proposed model can be considered the duration of intervals $(15 \mathrm{~min}$ ) that were applied in a discrete model. These intervals might be taken as too long to record all arrivals and departures of vehicles. In case of higher intensities (more arrivals and departures in shorter time), this model could provide less reliable results. However, it is not the topic for a parking time spent by customers at this type and size parking lot of supermarket. In this case, i.e., higher intensities, the shorter interval can be applied or the usage of model with continuous Markov chain would be more appropriate to the situation. Nevertheless, such solution requires further technical means and puts considerably greater demands on data collection and a practical implementation of the model. More detail system of states of parking process can be possibly defined, and this choice depends on intensity of utilization of parking lot and required complexity of prediction.

\section{Acknowledgements}

We wish to thank various people for their contribution and valuable technical support to this project; staff of Dept of Vehicles and Ground Transport, Faculty of Engineering, Czech University of Life Sciences Prague, for their help in collecting the plant data and all the technicians who helped us in handling the instruments.

\section{Funding}

Internal grant agency of the Czech University of Life Sciences Prague (Project No 31150/1312/313120).

\section{Author contributions}

Miroslav Rủžička was responsible for the design and organization of traffic survey, data collection and development of the data analysis.

Helena Brožová was responsible for data interpretation and proposal of model. 


\section{Disclosure statement}

The authors of this paper receive research funding from Czech University of Life Sciences Prague, which is developing products related to research described in this paper.

In addition, the one of authors serves as a consultant to Lidl Holding s. r. o. (Czech Republic) and receives compensation for these services.

The terms of this arrangement have been reviewed and approved by Czech University of Life Sciences Prague in accordance with its policy on objectivity in research.

\section{References}

An, S.; Han, B.; Wang, J. 2004. Study of the mode of real-time and dynamic parking guidance and information systems based on fuzzy clustering analysis, in Proceedings of 2004 International Conference on Machine Learning and Cybernetics, 26-29 August 2004, Shanghai, China, 2790-2794.

https://doi.org/10.1109/ICMLC.2004.1378506

Balzano, W.; Vitale, F. 2017. DiG-Park: a smart parking availability searching method using V2V/V2I and DGP-class problem, in 2017 31st International Conference on Advanced Information Networking and Applications Workshops (WAINA), 27-29 March 2017, Taipei, Taiwan, 698-703.

https://doi.org/10.1109/WAINA.2017.104

Bosserhoff, D. 2009. Methoden zur Abschätzung des Verkehrsaufkommens durch kommerzielle Einrichtungen und andere Vorhaben der Bauleitplanung, in Mariánské Lázně 2009: Ddoprava generovaná komerčními zónami: sborník přednášek konference, 12.-13. listopadu 2009, Mariánské Lázně, Česká Republika, 23-39. (in German).

Caicedo, F. 2009. The use of space availability information in "PARC" systems to reduce search times in parking facilities, Transportation Research Part C: Emerging Technologies 17(1): 56-68. https://doi.org/10.1016/j.trc.2008.07.001

Caicedo, F.; Blazquez, C.; Miranda, P. 2012. Prediction of parking space availability in real time, Expert Systems with Applications 39(8): 7281-7290. https://doi.org/10.1016/j.eswa.2012.01.091

Caliskan, M.; Barthels, A.; Scheuermann, B.; Mauve, M. 2007. Predicting parking lot occupancy in vehicular ad hoc networks, in 2007 IEEE 65th Vehicular Technology Conference VTC2007-Spring, 22-25 April 2007, Dublin, Ireland, 277-281. https://doi.org/10.1109/VETECS.2007.69

Caliskan, M.; Graupner, D.; Mauve, M. 2006. Decentralized discovery of free parking places, in VANET'06: Proceedings of the 3rd International Workshop on Vehicular Ad Hoc Networks, 29 September 2006, Los Angeles, CA, US, 30-39. https://doi.org/10.1145/1161064.1161070

Camero, A.; Toutouh, J.; Stolfi, D. H.; Alba, E. 2019. Evolutionary deep learning for car park occupancy prediction in smart cities, Lecture Notes in Computer Science 11353: 386-401. https://doi.org/10.1007/978-3-030-05348-2_32

Chen, N.; Wang, L.; Jia, L.; Dong, H.; Li, H. 2016. Parking survey made efficient in intelligent parking systems, Procedia Engineering 137: 487-495.

https://doi.org//10.1016/j.proeng.2016.01.284

Cheng, T.; Tai, M.; Ma, Z. 2012. The model of parking demand forecast for the urban CCD, Energy Procedia 16: 1393-1400. https://doi.org/10.1016/j.egypro.2012.01.221

ČSN 73 6056. Odstavné a parkovací plochy silničních vozidel. (in Czech).

ČSN 73 6110. Projektování místních komunikací. (in Czech).
D’Aloia, M.; Rizzi, M.; Russo, R.; Notarnicola, M.; Pellicani, L. 2015. A marker-based image processing method for detecting available parking slots from UAVs, Lecture Notes in Computer Science 9281: 275-281. https://doi.org//10.1007/978-3-319-23222-5_34

De Groot, J. I. M.; Steg, L.; Dicke, M. 2008. Transportation trends from a moral perspective: value orientations, norms and reducing car use, in F. N. Gustavsson (Ed.). New Transportation Research Progress, 67-91.

Hendricks, S.; Outwater, M. 1998. Demand forecasting model for park-and-ride lots in King County, Washington, Transportation Research Record: Journal of the Transportation Research Board 1623: 80-87. https://doi.org/10.3141/1623-11

Inaba, K.; Shibui, M.; Naganawa, T.; Ogiwara, M.; Yoshikai, N. 2001. Intelligent parking reservation service on the Internet, in Proceedings 2001 Symposium on Applications and the Internet Workshops, 8-12 January 2001, San Diego, CA, US, 159-164. https://doi.org/10.1109/SAINTW.2001.998224

Khaliq, A.; Van der Waerden, P.; Janssens, D.; Wetsa, G. 2019. A conceptual framework for forecasting car driver's on-street parking decisions, Transportation Research Procedia 37: 131138. https://doi.org/10.1016/j.trpro.2018.12.175

Klappenecker, A.; Lee, H.; Welch, J. L. 2014. Finding available parking spaces made easy, Ad Hoc Networks 12: 243-249. https://doi.org/10.1016/j.adhoc.2012.03.002

Lam, W. H. K.; Li, Z.-C.; Huang, H.-J.; Wong, S. C. 2006. Modeling time-dependent travel choice problems in road networks with multiple user classes and multiple parking facilities, Transportation Research Part B: Methodological 40(5): 368-395. https://doi.org/10.1016/j.trb.2005.05.003

Li, B.; Pei, Y.; Wu, H.; Huang, D. 2017. MADM-based smart parking guidance algorithm, PLoS One 12(12): e0188283. https://doi.org/10.1371/journal.pone.0188283

Li, P.; Li, D.; Zhang, X. 2014. CGPS: a collaborative game in parking-lot search, Advances in Intelligent Systems and Computing 250: 105-113. https://doi.org/10.1007/978-81-322-1695-7_13

Liang, W.; Zhang, Y.; Hu, J.; Wang, X. 2017. A personalized route guidance approach for urban travelling and parking to a shopping mall, in 2017 4th International Conference on Transportation Information and Safety (ICTIS), 8-10 August 2017, Banff, Canada, 319-324.

https://doi.org/10.1109/ICTIS.2017.8047783

Lin, T.; Rivano, H.; Le Mouël, F. 2017. A survey of smart parking solutions, IEEE Transactions on Intelligent Transportation Systems 18(12): 3229-3253.

https://doi.org//10.1109/TITS.2017.2685143

Mamandi, A.; Yousefi, S.; Atani, R. E. 2015. Game theory-based and heuristic algorithms for parking-lot search, in 2015 International Symposium on Computer Science and Software Engineering (CSSE), 18-19 August 2015, Tabriz, Iran, 1-8. https://doi.org/10.1109/CSICSSE.2015.7369235

Martolos, J.; Šindlerová, V.; Bartoš, L.; Mužík, J. 2013. Metody prognózy intenzit generované dopravy: monografie. Plzeň: EDIP. 108 s. (in Czech).

Mathur, S.; Jin, T.; Kasturirangan, N.; Chandrasekaran, J.; Xue, W.; Gruteser, M.; Trappe, W. 2010. ParkNet: drive-by sensing of road-side parking statistics, in MobiSys'10: Proceedings of the 8th International Conference on Mobile Systems, Applications, and Services, 15-18 June 2010, San Francisco, CA, US, 123-136. https://doi.org/10.1145/1814433.1814448

Oh, B.-W.; Lee, S.-Y.; Kim, M.-S.; Yang, Y.-K. 2002. Spatial applications using $4 \mathrm{~S}$ technology for mobile environment, in IEEE International Geoscience and Remote Sensing Symposium, 24-28 June 2002, Toronto, Canada, 2444-2446. https://doi.org/10.1109/IGARSS.2002.1026572 
Rada hlavního města Prahy. 2016. Pražské stavební předpisy 2016: 10. nařízení, kterým se stanovují obecné požadavky na využívání území a technické požadavky na stavby v hlavním městě Praze. 59 s. Available from Internet: https://www.praha. eu/file/2188282/narizeni_c._10.pdf (in Czech).

Richter, F.; Di Martino, S.; Mattfeld, D. C. 2014. Temporal and spatial clustering for a parking prediction service, in 2014 IEEE 26th International Conference on Tools with Artificial Intelligence, 10-12 November 2014, Limassol, Cyprus, 278-282. https://doi.org/10.1109/ICTAI.2014.49

Rong, Y.; Xu, Z.; Yan, R.; Ma, X. 2018. Du-parking: spatiotemporal big data tells you realtime parking availability, in KDD'18: Proceedings of the 24th ACM SIGKDD International Conference on Knowledge Discovery \& Data Mining, 19-23 August 2018, London, UK, 646-654. https://doi.org/10.1145/3219819.3219876

Schlote, A.; King, C.; Crisostomi, E.; Shorten, R. 2014. Delaytolerant stochastic algorithms for parking space assignment, IEEE Transactions on Intelligent Transportation Systems 15(5): 1922-1935. https://doi.org/10.1109/TITS.2014.2304356

Serfozo, R. 2009. Basics of Applied Stochastic Processes. Springer. 443 p. https://doi.org/10.1007/978-3-540-89332-5

Shoup, D. C. 1999. The trouble with minimum parking requirements, Transportation Research Part A: Policy and Practice 33(7-8): 549-574. https://doi.org/10.1016/S0965-8564(99)00007-5

Stolfi, D. H.; Alba, E.; Yao, X. 2017. Predicting car park occupancy rates in smart cities, Lecture Notes in Computer Science 10268: 107-117.

https://doi.org/10.1007/978-3-319-59513-9_11

Sun, M.; Li, Z.; Peng, L.; Li, H.; Fang, X. 2018. FLOPS: an efficient and high-precision prediction on available parking spaces in a long time-span, in 2018 21st International Conference on Intelligent Transportation Systems (ITSC), 4-7 November 2018, Maui, HI, US, 2937-2942.

https://doi.org/10.1109/ITSC.2018.8569435

Tilahun, S. L.; Di Marzo Serugendo, G. 2017. Cooperative multiagent system for parking availability prediction based on time varying dynamic Markov chains, Journal of Advanced Transportation 2017: 1760842. https://doi.org/10.1155/2017/1760842

US 2004/0032342. Method and System for Projecting Dynamic Parking Availability Based on an Ongoing Survey for Remote Lots with High Demand. United States Patent Application.

Yan, X.; Levine, J.; Marans, R. 2019. The effectiveness of parking policies to reduce parking demand pressure and car use, Transport Policy 73: 41-50.

https://doi.org/10.1016/j.tranpol.2018.10.009

Yang, Z.; Liu, H.; Wang, X. 2003. The research on the key technologies for improving efficiency of parking guidance system, in Proceedings of the 2003 IEEE International Conference on Intelligent Transportation Systems, 12-15 October 2003, Shanghai, China, 1177-1182.

https://doi.org/10.1109/ITSC.2003.1252670

Zhao, Z.; Kim, J.-W.; Zhang, L. 2018. Parking data collection, storage and mining in smart city, in ICBDR 2018: Proceedings of the 2nd International Conference on Big Data Research, 27-29 October 2018, Weihai, China, 95-99.

https://doi.org//10.1145/3291801.3291841 